\title{
COMMINUTED INTRA ARTICULAR FRACTURE OF DISTAL RADIUS: OUTCOME OF MANAGEMENT WITH CLOSED REDUCTION AND PERCUTANEOUS PINNING.
}

\begin{abstract}
1. MBBS, MS
Associate Professor Orthopaedic Peoples University of Medical \& Health Sciences, Nawabshah.

2. MBBS, MS

Associate Professor Orthopaedic Peoples University of Medical \& Health Sciences, Nawabshah.

3. MBBS, FCPS

Assistant Professor Orthopaedic Peoples University of Medical \& Health Sciences, Nawabshah.

4. MBBS, MS

Assistant Professor Orthopaedic Peoples University of Medical \& Health Sciences, Nawabshah.

5. MBBS, MS

Assistant Professor Orthopaedic Peoples University of Medical \& Health Sciences, Nawabshah.
\end{abstract}

Correspondence Address: Dr. Syed Karam Ali Shah, Orthopaedic Department

Peoples University of Medical \& Health Sciences, Nawabshah. karam alishah@yahoo.com

Article received on:

26/03/2019

Accepted for publication:

25/07/2019

Received after proof reading: $30 / 09 / 2019$

\begin{abstract}
Karam Ali Shah', Saeed Ali Shah², Zahoor Illahi Soomro ${ }^{3}$, Allah Nawaz Abbasi ${ }^{4}$,
\end{abstract} Muhammed Azeem Akhund ${ }^{5}$

ABSTRACT... Objectives: To determine the outcome and various complications in the management of comminuted intra articular fractures of distal radius in adults treated with closed reduction associated with Percutaneous Pinning. Study Design: Observational study. Setting: Department of Orthopaedic PUMHS, Nawabshah. Period: January 2017 to December 2018. Material and Methods: 45 consecutive cases of closed comminuted intra articular fractures of distal radius matching the inclusion criteria, all patients were adult aged between 23 - 38 years having Gartland and Werly type II and III fractures of 6 to 7 days duration. The data collected was statistically analysed and the results were tabulated. Results: 45 cases of closed intra articular fractures of distal radius were assessed, out of these 20 cases have Gartland type II and 25 cases have Gartland type III fractures. The age of patient was ranged between $23-38$ years (mean $34+4.63)$, majority (55.6\%) of patients were male. The left side of fractures were present in $66.3 \%$ of cases. All the patients checked for complications and that were seen in only 07 cases consisting of pin tract infection, reduced grip strength and finger stiffness. At the end of study period the range of movements in different directed were checked and evaluation was done according to modified Demerit scoring system. Conclusion: Closed reduction of distal radius with percutaneous pinning in comminuted intra articular fractures gives promising excellent results, it is a simple and minimal procedure providing anatomic reduction, fixation of fracture and maintenance of reduction with an suitable technique of immobilization.

Key words: Comminuted Fractures, Closed Reduction, Distal Radius, Percutaneous Pinning.

Article Citation: Shah KA, Shah SA, Soomro ZI, Abbasi AN, Akhund MA. The comminuted intra articular fracture of distal radius: Management with closed reduction and percutaneous pinning. Professional Med J 2019; 26(10):1697-1701. DOI: 10.29309/TPMJ/2019.26.10.3448

\section{INTRODUCTION}

The fractures of distal radius are the commonest fractures occurs mostly in young adults (12-25 years) and in persons above 65 years of age. ${ }^{1}$ There is a noticeable strife concerning the surpass treatment options for these fractures. ${ }^{2}$

The fracture of distal radius remains a remedial instigation since the description of Colles in the year 1814. The closed treatment of unstable and comminuted intra articular fracture may leads to permanent deformities, pain and disturbance in the functions due to various complications like collapse, loss of palmar tilt, radial shortening, and articular incongruent. ${ }^{3}$ The skeletal fixation to maintain the reduction is necessary as the closed reduction and immobilization of displaced fractures may cause early displacement. ${ }^{4}$

Open reduction - internal fixation (ORIF) was popular technique during last decade in the management of distal radial fractures. ${ }^{5}$ The functional rehabilitation was the obvious disadvantage in this procedure, but some difficulties were also there ${ }^{6}$, and traditionally the surgical treatment is reserved for displaced, irreducible fractures or reducible but unstable fractures. ${ }^{7}$

Closed reduction with percutaneous pinning remains globally a popular method for many years, the procedure is less invasive, in which the consultant have a choice of wide variety of pinning. ${ }^{8}$ The benefits of this procedure are that 
it is a swift and technically less demanding in comparison to more complex forms of fixation and there is less destruction of soft tissues. ${ }^{9}$ The drawbacks of this technique are the complications of pin-site infection, perfectness is less than open technique and the stability of fixation is also less in comparison to plating. ${ }^{10}$

External fixation is a well known method and is populated by more than 25 brands of external fixators $^{8,11}$, which achieve reduction and fixation without loss of position and acceptable functional results. $^{12}$ The likely complications of this procedure are re-displacement, pin-tract infection and late collapse. ${ }^{13}$

The current observational study was designed to evaluate the outcome and to determine the various complications arises in the management of unstable and comminuted intra articular fracture of distal radius in adult population treated with closed reduction and percutaneous pinning.

\section{METHODS}

This observational study was conducted in the department of Orthopaedic PUMHS, Nawabshah, from January 2017 to December 2018, on 45 consecutive cases of closed comminuted intra articular fractures of distal radius. The cases included in this were adult patients aged above 18 years having Gartland and Werly type II and III fractures of 6 to 7 days duration. The cases excluded from the study were open fractures, pathologic fractures and patients having co - morbidity like diabetes mellitus. After initial resuscitation, thorough clinical examination done and all base line laboratory investigations and $x$-rays were obtained. The demographic and clinical data was recorded on a proforma. The patients were informed about the study and surgery and a written consent was taken. Preoperatively; Antero -Posterior (AP) and Lateral radiographs of affected limb were taken and their radiological parameters like radial height $(\mathrm{RH})$, radial inclination (RI), and ulnar variance (UV) were measured. All of the patient were gone for closed reduction with percutaneous $\mathrm{K}$ - wiring. The fracture was reduced by traction and counter traction and checked by fluoroscopy, $3-4 \mathrm{~K}-$ wires were passed and after confirmation under $\mathrm{C}$ - arm the wires were bent and cut, a sterile gauze was placed beneath the pin. The plaster cast was applied below the elbow upto metacarpal heads with wrist in neutral position. On 2nd postoperative day early mobilization was started. The patients went home and they asked for follow up weekly. Functional outcome like union, healing and any complication were assessed. Patients were also checked for the range of movements. After 6 weeks, the $\mathrm{K}$ - wires and cast was removed and the procedure of physiotherapy started. After six weeks all the patients were advised for follow up at an interval of 3 months and 6 months. Postoperatively at 6 weeks, radiological parameters were assessed, that is, radial height $(R H)$, radial inclination (RI), and ulnar variance (UV) were measured on X-rays in AP and lateral views. The data collected was processed statistically by using statistical package for social sciences (SPSS) version 23, and the results were tabulated.

\section{RESULTS}

The current study was performed on 45 cases of closed intra articular fractures of distal radius, out of these 20 cases have Gartland type II and 25 cases have Gartland type III fractures. The age of patient was ranged between 23 - 38 years (mean $34+4.63)$, majority $(55.6 \%)$ of patients were male. The left side of fractures were present in $66.3 \%$ of cases and right side in $33.3 \%$ (Table-I). All the patients checked for complications and that were seen in only seven cases consisting of pin tract infection in three cases, reduced grip strength and finger stiffness each in two cases (Figure-1). At the end of study period the range of movements in different directed were checked (Table-II) and evaluation was done according to modified Demerit scoring system ${ }^{14}$ (Figure-2).

\begin{tabular}{|l|c|c|}
\hline Total Patients & (No) & 45 \\
\hline Male & (No \%) & $25(55.6)$ \\
\hline Female & (No \%) & $20(44.4)$ \\
\hline Age & (Years) & $23-38$ \\
\hline Mean & $( \pm$ SD) & $34.72 \pm 4.63$ \\
\hline Right Side & (No \%) & $30(66.7)$ \\
\hline Left Side & (No \%) & $15(33.3)$ \\
\hline & \multicolumn{2}{|c|}{ Table-l. Demographic data } \\
\end{tabular}




\begin{tabular}{|l|c|}
\hline \multicolumn{1}{|c|}{ Movement Type } & Mean \pm SD \\
\hline Palmar Flexion & $60.4 \pm 5.0$ \\
\hline Dorsiflexion & $58.2 \pm 3.8$ \\
\hline Supination & $66.3 \pm 5.5$ \\
\hline Pronation & $62.5 \pm 2.0$ \\
\hline Ulnar Deviation & $22.1 \pm 3.1$ \\
\hline Radial Deviation & $15.7 \pm 1.0$ \\
\hline
\end{tabular}

Table-II. Mean range of movements

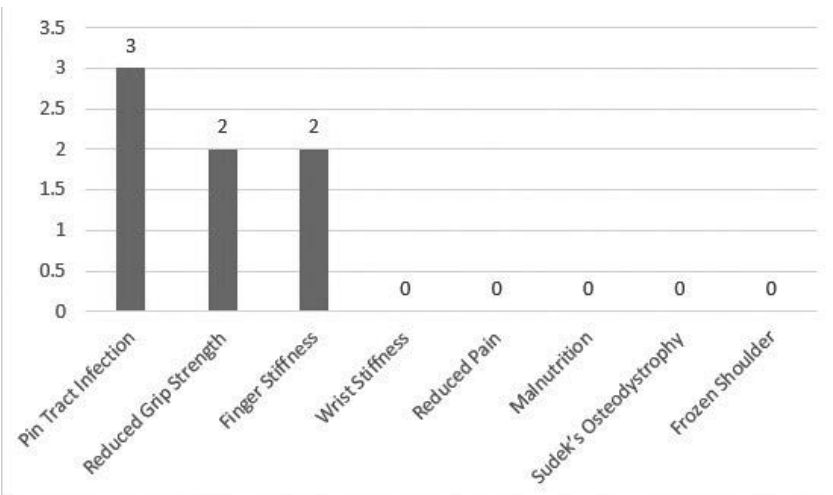

Figure-1. Complications

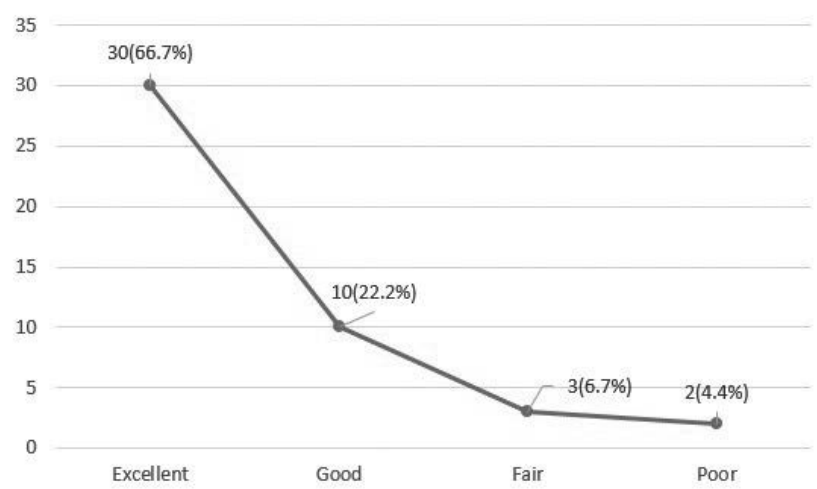

Figure-2. Patient's evaluation at the end of follow up. (Modified demerit scoring system).

\section{DISCUSSION}

The therapeutic gape between external fixators and plaster immobilization is bridged by percutaneous pin fixation in the management of fractures of distal radius ${ }^{15}$, it provides an additional stability to immobilization in a cast in unstable extra articular radial fractures in which anatomical reduction is required. ${ }^{16}$ In osteoprotic old age cases and in severely comminuted cases, this method give less encouraging results and is unsuitable for these patients, but as it is very simple to use and less intrusive than other methods like external fixation. ${ }^{17}$
The average age in our study was $34.72 \pm 4.63$, the male were $55.6 \%$ and female $44.4 \%$, with male to female ratio of 1:1.3. Similar findings were also stated by other researchers having more male patients in their study. ${ }^{18}$

Regarding complications we observed one case each of pin tract infection, reduced grip strength and finger stiffness, these results verify the studies of other workers who noted the similar complications, but most of these were pin tract infections that result in prolonged hospital stay and early wire removal. ${ }^{19-21}$

The assessment of movement in our study was excellent, we observe near about normal palmar flexion, dorsiflexion, supination, pronation, ulnar and radial deviation, similar and some better movements were achieved by other studies depending upon the duration of follow up time and better physiotherapy facilities. ${ }^{5,22}$

Based on objective and subjective criteria, residual deformity, and complications the activities of daily life were assessed at the end of follow up period using Demerit scoring system and majority of cases show excellent results, other studies mentioned in the literature also show similar results indicating the simplicity and perfectness of this familiar procedure..$^{23,24}$

\section{CONCLUSION}

We observed promising results in closed reduction of distal radius with percutaneous pinning in comminuted intra articular fractures, it is a simple and minimal procedure providing anatomic reduction, fixation of fracture and maintenance of reduction with an suitable technique of immobilization.

\section{Copyright $@ 25$ July, 2019.}

\section{REFERENCES}

1. Davis D I, Saratz M. Soft tissue complications of distal radius fractures. Hand Clin. 2010; 26(2):229-35.

2. Fanuele J, Koval K J, Lurie J, Zhou W, Tosteson A, et al. Distal radial fracture treatment: What you get may depend on your age and address. J Bone Joint Surg Am. 2009 Jun 1; 91(6): 1313-9. doi: 10.2106/JBJS.H.00448. 
3. Kurup H V, Mandalia V M, Shaju K A, Singh B, Beaumont $A$ R. Late collapse of distal radius fractures after K-wire removal: Is it significant?. J Orthop Traumatol. 2008; 9(2):69-72.

4. Egmond P W, Schipper I B, van Luijt P A. Displaced distal forearm fractures in children with an indication for reduction under general anesthesia should be percutaneously fixated. Eur J Orthop Surg Traumatol. 2012 Apr; 22(3): 201-7. doi: 10.1007/s00590-011-08266.

5. Meena S, Sharma P, Sambharia A K, Dawar A. Fractures of distal radius: An overview. J Family Med Prim Care. 2014; 3(4):325-32.

6. Cosgrove W J, Loucks D P. Water management: Current and future challenges and research directions. Water Resour Res. 2015; 51(6): 4823-39. doi:10.1002/2014WR016869.

7. Walenkamp M M, Vos L M, Strackee S D, Goslings J C, Schep $\mathrm{N} \mathrm{W}$. The unstable distal radius fracture-how do we define it? A Systematic Review. J Wrist Surg. 2015; 4(4):307-16.

8. Popkin C A, Rosenwasser K A, Ellis H B Jr. Pediatric and adolescent t-type distal humerus fractures. JAAOS Global Research \& Reviews. 2017; 1 (8):e040. doi: 10.5435/JAAOSGlobal-D-17-00040.

9. Guity MR, Otaghvar HRA, Tovakolli M, Farhoud A. Closed reduction and percutaneous pinning of distal radius fractures without intraoperative X-Ray. J Orthop Spine Trauma. 2016; 2(1):e1784. Available from; https://www.researchgate.net/publication/296514001_ Closed_Reduction_and_Percutaneous_Pinning_of_Distal_Radius_Fracture_Without_Intra-Operative_X-Ray.

10. Xue $X H$ and Pan $X Y$. A meta-analysis of distal radial fractures comparing closed reduction and pinning fixation with open reduction and internal fixation. Austin Orthop. 2017; 2(1): 1004. Available from; austinpublishinggroup.com/austin-orthopedics/ download.php?file =fulltext/...id 1004 .

11. Özkul B, Saygılı M S, Dinçel Y M, Bayhan I A, Akbulut D, Demir B. Comparative results of external fixation, plating, or nonoperative management for diaphyseal clavicle fractures. Med Princ Pract. 2017; 26(5):45863.

12. Kazemian G H, Emami M, Manafi A, Najafi F, Najafi M A. External Fixation vs. Skeletal traction for treatment of intertrochanteric fractures in the elderly. Trauma Mon. 2016 February; 21(1): e15477. DOI: 10.5812/ traumamon.15477.
13. Mathews $A$ L, Chung $K$ C. Management of complications of distal radius fractures. Hand Clin. 2015; 31(2): 205-15.

14. Young BT, Rayan GM. Outcome following nonoperative treatment of displaced distal radius fractures in low demand patient older than 60 years. J Hand Surg Am 2000; 25:19-28.

15. Sridhar D K, Raghavendra $T S$, Mahida JR. Comparative study between percutaneous pinning and ligamentotaxis using external fixator in the management of distal end radius fracture in adults: A prospective study. International Journal of Research in Orthopaedics. Int J Res Orthop. 2017 Mar; 3(2):23541.

16. Patil P, Gaonkar K, Patil A, Gaonkar N, Gupta K, Patel N, et al. Prospective study of treatment of extraarticular fractures of distal end radius by cross $\mathrm{K}$ wire fixation and cast immobilisation and its comparison with Kapandji's method of intrafocal pinning anatomically and functionally. Int J Res Med Sci. 2015 Apr; 3(4):88390.

17. Singh $H$, Misra $R \mathrm{~K}$, Kaur M. Management of proximal tibia fractures using wire based circular external fixator. J Clin Diagn Res. 2015; 9(9):RC01-4.

18. Pradhan R L, Lakhey S, Pandey B K, Manandhar R R, Rijal K P, Sharma S. External and internal fi xation for comminuted intra-articular fractures of distal radius. Kathmandu Uni Med J. 2009; 7(28):369-73.

19. Lakshmanan P, Dixit V, Reed MR, Sher JL. Infection rate of Krischner wire fixation for distal radius fracture. $J$ Orthop Surg (Hong Kong) 2010; 18:85-6.

20. Blakeney WG. Stabilisations and treatment of colles fractures in elderly patients. Clin Interv Aging 2010; 5:337-44.

21. Madhukar KT, Gopalkrishna G, Mohan JA. Percutaneous K-wire fixation of distal radius fractures: Our results of leaving the wire outside. Inter $\mathrm{J}$ Health Alied Sci. 2013; 2(1):23-9.

22. Gauresh V. Distal end radius fractures: Evaluation of results of various treatments and assessment of treatment choice. Chinese J Traumatol. 2014; $17(4): 214-9$.

23. Bagul RR, Deshmukh A, Salgia A, Agarwal T, Rajani $D$, Sooknundan M. Comparative evaluation in the measurement of the radial height, radial inclination, and ulnar variance in fracture distal end radius treated conservatively by closed reduction and cast and closed reduction, Kirschner wire and cast. Med J DY Patil Univ. 2014; 7:590-5. 
24. Venkatesh RB, Maranna GK, Narayanappa RKB. A comparative study between closed reduction and cast application versus percutaneous $k$ - wire fixation for extra-articular fracture distal end of radius. JCDR. 2016; 10(2):RC05-RC09.

\section{AUTHORSHIP AND CONTRIBUTION DECLARATION}

\begin{tabular}{|c|l|l|}
\hline Sr. \# & \multicolumn{1}{|c|}{ Author-s Full Name } & \multicolumn{1}{|c|}{ Contribution to the paper } \\
\hline 1 & Karam Ali Shah & Concept \& Design of Study \\
2 & Saeed Ali Shah & Drafting. \\
\hline 3 & Zahoor Illahi Soomro & Data analysis. \\
4 & Allah Nawaz Abbasi & $\begin{array}{l}\text { Data analysis, Revisiting } \\
\text { Critically. } \\
\text { Final Approval of version. }\end{array}$ \\
\hline 5 & M. Azeem Akhund & Fignature \\
\hline
\end{tabular}

